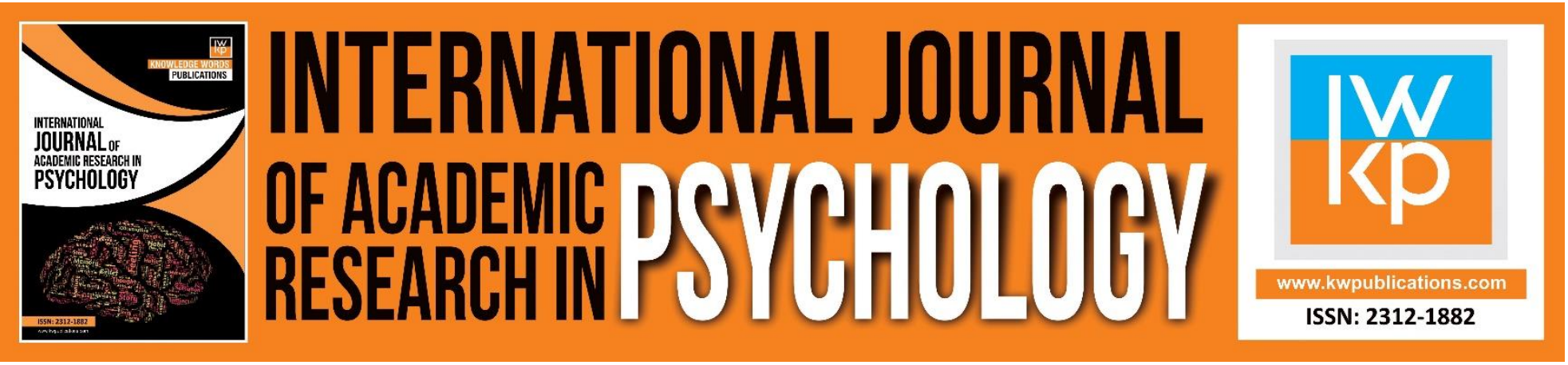

\title{
Shifts in Manager's Behavior as a Function of Enabling and Debilitating Contexts
}

\author{
R B N Sinha, N Lakshmi
}

To Link this Article: http://dx.doi.org/10.46886/IJARP/v4-i1/2597

DOI: $10.46886 /$ IJARP/v4-i1/2597

Received: 13 May 2017, Revised: 11 June 2017, Accepted: 30 June 2017

Published Online: 24 July 2017

In-Text Citation: (Sinha, \& Lakshmi, 2017)

To Cite this Article: Sinha, R. B. N., Lakshmi, N. (2017). Shifts in Manager's Behavior as a Function of Enabling and Debilitating Contexts. International Journal of Academic Research in Psychology. 4(1), 1-10.

\section{Copyright: (c) 2017 The Author(s)}

Published by Knowledge Words Publications (www.kwpublications.com)

This article is published under the Creative Commons Attribution (CC BY 4.0) license. Anyone may reproduce, distribute, translate and create derivative works of this article (for both commercial and non-commercial purposes), subject to full attribution to the original publication and authors. The full terms of this license may be seen at: $\underline{\text { http://creativecommons.org/licences/by/4.0/legalcode }}$

Vol. 4, No. 1, 2017, Pg. 1 - 10

https://kwpublications.com/journals/journaldetail/IJARP

JOURNAL HOMEPAGE

Full Terms \& Conditions of access and use can be found at https://kwpublications.com/pages/detail/publication-ethics 


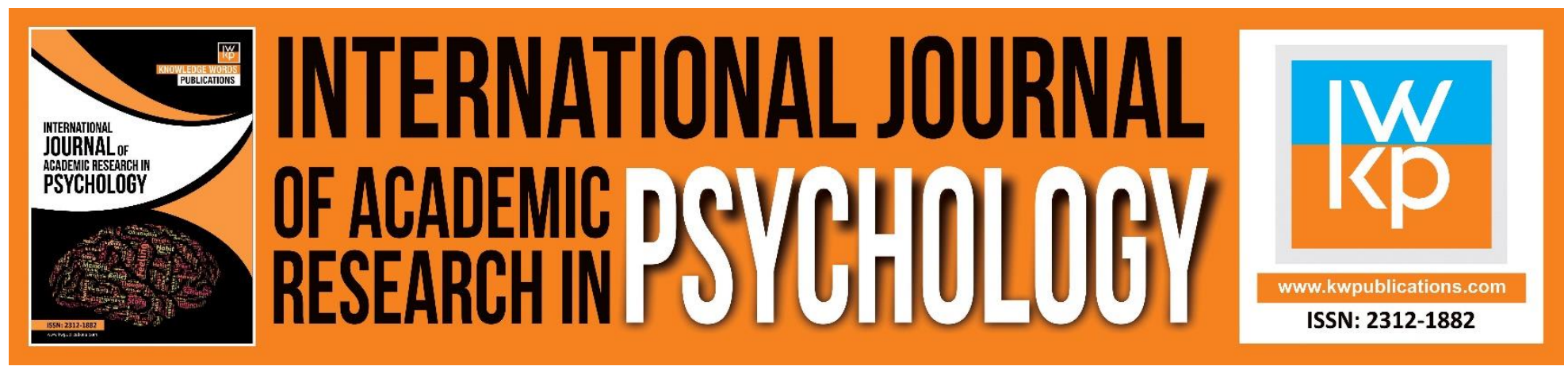

\title{
Shifts in Manager's Behavior as a Function of Enabling and Debilitating Contexts
}

\author{
R B N Sinha, N Lakshmi
}

Professor of Psychology, Coordinator, MBA, B S College, Danapur, Patna 800012 \& Honorary Faculty, ASSERT Institute of Management Studies, Patna, Head, Deptt. of Management Studies,

Galgotias College of Engineering \& Technology, Greater Noida (India).

Email: rbns2@rediffmail.com, nirupa.lakshmi@gmail.com

\begin{abstract}
A sample of 150 respondents, 50 from each of three different locations in India, participated in a study that explored the shifts in the behavior of managers when they moved from disabling to enabling or from enabling to disabling context. The results were mixed in showing that the behavior in some instances improved as a function of the change from disabling to enabling and reversed as a result of the change from enabling to disabling context. Some of the behaviors were more positive in the enabling than in the disabling context. The paper suggests a need to explore the issues further. Keywords: Context, Disabling, Enabling.

\section{Introduction}

Cultures differ in context orientation. Some are high and while others are low. In the latter, people tend to think in terms of abstract principles and norms (Hall, 1976). A number of investigators (Hall, 1981; Hall \& Hall, 1990; Triandis, 1984; Trompenaars, 1993) reported that Western cultures are low on context sensitivity while Eastern culture such as China, India and South Korea are high on context sensitivity (Miller, 1984; Markus \& Kitayama, 1991). Indians, however, are highly sensitive to contexts in their thoughts and practices (Ramanujan, 1989). Hughes (2002) also reported that Indians think, talk and act differently with regard to the same person in the same situation at the same point of time. In a more recent study by Sinha et al. (2010) confirmed that Indians tend to sense others' mindset, selectively relate to those who are likely to be useful, judge the right time to think to initiate action and reach out to avail of opportunities. Their context sensitivity was expressed in the following concerns, abilities and behaviors. For example, some of the statements are as follows: to be concerned about what others think of them, to have ability to figure out what others expect, and to behave accordingly, to sense what others mean and intend. Indians tend to behave differently in different context and they tend to balance their thought and action in order to function effectively.
\end{abstract}


In a high context cultures, people tend to rely on their history, their status, their relationships and a plethora of other information, including religion, to assign meaning to an event. In a collectivist culture, people paid more attention to context than did people from individualist culture (Gudykunst, 1983). Gupta (2002) found that cooperative behavior and team work among Indians are extremely difficult in organizational context, though group solidarity in well known in times of crisis in Indian families. Another series of studies (e.g., Roland, 1988; Sinha \& Kanungo, 1997) showed that Indians are sensitive to their contexts. They have been culturally socialized to view events and episodes from a long term perspectives. It has been found that majority of Indian perceive a situation and the responses to it as one episode in-on- going flow of interactive relationship between situations and responses (Sinha \& Sinha, 1995). In the West people apply abstract principles and generalized norms to decide how to behave in different situations whereas Indians organize their thoughts, feelings and behaviours in order to meet specif ic contextual demands. Contexts have three dimensions of desha (place), kala (time) and patra (pe rson), each having an enabling or debilitating potentials. Indians behave differently with different persons and different places as demanded by a situation - being positive in enabling and negative in disabling contexts (Sinha, 2009).

Enabling and debilitating contexts are likely to affect human behavior all over the world. Enabling contexts elicit different behavior. An organization having enabling contexts are characterized by a reasonable degree of security of job, opportunity and challenges to show their worth, a fair chance of getting rewarded for initiative and performance etc. However, Indians react to them sharply. Sinha et al. $(2001,2004)$ found that disabling contexts are more pervasive in the country. Further, Sinha et al. (2010) conducted a study in which four scenarios were given to the respondents to examine the extent to which a manager was likely to shift his behavior as a function of the replacement of a disabling superior with an enabling superior (person effect) and takeover of a disabling organization by an enabling one (place effect). The first two scenarios were compared to see how a manager was likely to shift his behavior in case a disabling boss was replaced with an enabling one. The disabling and enabling conditions disclosed that the manager was likely to shift his behavior significantly in all respects, except one- flattering the boss. The manager was more likely to turn highly motivated to perform well, come up with new innovative ideas and share them with the boss, communicate employees' feelings to the boss, and emulate the boss's style, but changing from imposing on his subordinates under disabling boss to encouraging and inspiring them under the enabling boss. The next two scenarios were compared to see how a manager was likely to shift his behavior in case of disabling and enabling condition of the organization. They found that a disabling context changes into enabling one, people were likely to shift towards more positive behavior. Sinha and his associates did not examine to see how a manager would likely to shift his behavior in case of enabling to disabling condition of the context (place). The present paper attempts to explore the possibility to shift in behavior and proposed the following hypotheses for verification.

Hypothesis 1 An enabling context will elicit more positive behavior than a disabling context.

Hypothesis 2 A changes in manager's placement from disabling to enabling will lead to move towards more positive and less negative behavior. 
INTERNATIONAL JOURNAL OF ACADEMIC RESEARCH IN PSYCHOLOGY

Vol. 4, No. 1, 2017, E-ISSN: 2312-1882 @ 2017 KWP

\section{Hypothesis 3 A changes in manager's placement from enabling to disabling will cause a reversal towards less positive behavior and more negative behavior.}

\section{Method \\ Sample}

The sample comprised of 150 respondents drawn from three locations namely, Patna, Delhi and Mumbai. In all three locations, a sample of 50 respondents from each location participated in the study. They were the ones who were willing to participate. Fifty per cent of the respondents were Ph. D., 48 per cent postgraduate degrees holders and the remaining two per cent doing graduation. The respondents were on average 30.81 ( $S D=11.21)$ yrs old with the range of 20 to $75 y$ rs. They had an average of $7.56(S D=9.28)$ years of working experience. The three samples differed significantly in terms of age $\left(F_{2,147}=7.76, p<.01\right)$. However, Patna had the highest meanage $(M=35.24 ; S D=15.86)$ followed by Mumbai $(M=30.38 ; S D=7.70)$ and Delhi $(M=26.82 ; S D=5.86)$. The majority (65.30\%) were males.

\section{Measures}

A questionnaire consisting of three parts was developed. Part I had two scenarios.

First scenario, in which two civil engineers (Ashok and Vivek) were graduated from a highly reputed college in Bangalore. The GCC International which has specialized in constructing rail cum roadbridge at several places in India and abroad, hired them. Ashok was placed at a site in Bihar where a bridge was being constructed over the Ganges. Vivek was placed at a site in Gujarat where a bridge was being constructed over Narmada. Within three years, both Ashok and Vivek got two promotions and three slabs of raise in their pay and perks. The respondents had to guess the likelihood of 11 behaviors which led to their success.

Second scenario stated the following: As a company policy, Ashok and Vivek were transferred after three years, Ashok being placed at a new site in Gujarat and Vivek at a new site in Bihar. Respondents were again asked to guess how Ashok and Vivek would behave. In both scenarios, the respondents had to rate the likelihood of 11 behaviors that Ashok and Vivek might have performed in Scenario 1 and would perform in Scenario 2. The 11 behaviors that the respondents were asked to rate on a 4-point scale, ranging from Most Unlikely (1), Unlikely (2), Likely (3), and Most Likely (4). Behaviors are given in the result section. Samples of them were as follows:

1. Followed all rules and regulations of the company meticulously.

2. Encouraged and inspired his subordinates to get best out of them.

3. Will come up with new ideas that will improve his unit's performance.

4. Will keep his superiors pleased by telling how ideal bosses they are.

Part II of the questionnaire enquired about the age, gender, education, years of experiences etc. Part III had 10 statements regarding educational institutions, health facilities, job opportunities, transport and communications, law \& order situation, corruption level recreational facilities neighbourhood, pollution level and about people designed to measure about the city on a 4-point Likert type scale in which the respondents were residing. 
The study was based on the assumption that Bihar had a disabling while Gujarat had an enabling milieu. In order to substantiate it, the two states (Bihar and Gujarat) were also compared on number of dimensions. Gujarat was one of the highly developed states (ranked $5^{\text {th }}$ ) and Bihar (ranked $12^{\text {th }}$ ) on the basis of Gross State Domestic Product (GSDP) in 2014-2015 (Govt. of India, 2014). Gujarat state had 79.31 literacy rates whereas Bihar had 63.82 in 2011 (Census of India, 2011). Gujarat state has been ranked first amongst 20 major Indian states in terms of fixed capital investments and fourth in terms of total number of factories. Bihar's towns are far more crowded at 5,058 persons per sq km compared to 3,477 persons per sq km in Gujarat's urban areas. According to Niti Aayog data, per capita income in Gujarat at Rs 63,168 in 2013-14 at constant 2004-05 prices was about four times Bihar's per capita income, estimated at Rs 15,506. With regard to urbanization Bihar's had $2.5 \%$ where Gujarat 3.8\%. Forty-two per cent of Gujarat's population lives in towns and cities compared to 11 per cent in Bihar (Census of India, 2011). There are just a few instances that illustrate the wide gap in development of the two states. Bihar compares poorly on access to basic amenities such as treated drinking water in taps (3.1\% vs. $39.9 \%)$, electricity or lighting (16.4\% vs. $90.4 \%)$ and LPG for cooking (8.1\% vs. 38.3\%). On the basis of above description of the two places (Bihar \& Gujarat) where the managers were posted were considered as disabling (Bihar) and enabling (Gujarat). Data were collected from June to July 2016.

\section{Design}

A $2 \times 2 \times 3$ (Contexts $\times$ Persons $\times$ locations) factorial design was employed where the participants located at Patna, Delhi and Mumbai rated the positive and negative behaviors of two hypothetical managers, Ashok and Vivek, who worked and then shifted from disabling to enabling and from enabling to disabling conditions respectively.

\section{Results}

As noted above the hypotheses were that managers behave more positively under enabling condition than under disabling ones, and if they shifted from disabling to enabling condition, their behavior becomes more positive while shifting from enabling to disabling, they suffered a reversal from positive to negative. The hypotheses were partially supported in some of the eleven behaviors which were examined in the present study. The findings were reported in Table 1 which indicated the significant effects of contexts, persons and locations and Table 2 that contained the mean values.

Insert Table $1 \&$ Table 2 about Here

Table 1 disclosed that at least in two behaviors, the main effects of contexts were significant confirming hypothesis I. The mean scores of Tables 2 of these two behaviors showed that in the disabling $(M=1.78)$ condition both Ashok and Vivek followed rules and regulations more meticulously (Item no. 1$)$ than in the enabling $(M=1.76)$ condition. On the other hand, both Ashok and Vivek tended to inspired their subordinates to get best out of them (Item no. 5 ) in enabling ( $M$ $=1.62)$ condition than in the disabling $(M=1.52)$ ones.

There were five behaviors in which the shifts from disabling to enabling and from enabling to disabling were found to be statistically significant. It was clear from Table 1 which confirmed hypothesis two and three. Table 2 provided the details. It was found that when Ashok moved from 
disabling to enabling, he was reported more likely to inspired his subordinates in order to get best out of them (Item no. 5). When Vivek moved from enabling to disabling condition he was reported less likely to inspire his subordinates to get best out of them. Similarly, Ashok was reported to keep pleasing his superiors more likely when he moved from disabling to enabling while Vivek decreased this behavior when shifted from enabling to disabling. The remaining three behaviors (Item no. 6, 7, $\& 8)$ which were rather negative in nature, there trend was reverse i.e. Ashok was reported less likely to manipulate records to show his better performance to perceive just lucky and to visit his superiors at their residence offering services in enabling condition when shifted to disabling to enabling condition. On the other hand, Vivek was reported engaging in all these three behaviors more likely when he shifted from enabling to disabling condition. Thus, all three hypotheses were confirmed but only in sum behaviors not in all 11 behaviors which were included in the study.

So far as the main effects of persons and locations as well as their double and triple interactions were concerned, only one out of 11 behaviors revealed significant effects. They were not interest of the study and therefore ignored in discussion.

\section{Discussion}

The present study aimed to contribute to our understanding of how context affects managers' behavior in an organization setting. Earlier work by Sinha (2010) showed that Indians are highly sensitive to their contexts. If the context is enabling, they organize their mindset in order to behave more positively. However, when the context is disabling, they resort to more defensive and negative behaviors out of their concern for serving their interest in short term perspective. However, contexts are not static. They often change and may change from negative to positive or from positive to negative. It necessitated arguing that when a context changes from negative to positive, the persons within that context will also change from less to more positive or negative to positive. By the same token when a context deteriorates from positive to negative, the person within that context will also down grade their behaviors. Both anecdotal and empirical evidence have been reported to confirm these trends (Sinha, et al. 2010). Sinha (1974) for example, reported that a participatory leader reverse to authoritarian leadership when the organizational culture changed.

However, these trends still need further confirmation. One multi authored study by Sinha et al. (2010) that was conducted in 12 different locations in which the first author was also a collaborator examined more rigorously how shift in the context affects managers' behaviors. The study reported to either in superiors' behaviors from autocratic to participatory or the organization being transformed from short term profit making to long term performance as well as person originated management.

The findings confirmed that shift either in superiors' managerial styles or in the management of the organizations towards more positive side improves the various behaviors of managers. However, this study had a limitation that it did not examined whether a shift from more positive to negative managerial or organizational styles adversely affects managers' behaviors. The present study examined both the impacts of positive as well as negative shift in the contexts along with rechecking the main effects of positive and negative contexts.

The present study indeed confirmed that managers in at least in some cases behave more positively in enabling conditions and more negatively in disabling conditions. Furthermore, when condition shift from disabling to enabling, managers' behaviors improve. On the other hand, when 
the context turns to be negative managers' behavior becomes more negative. However, the trend was observed in some of the behaviors not in others may be because the contexts in this study operational zed differently than the previous study. Contexts of the managerial behaviors can have two levels: organization and the surroundings milieu. There is a vast literature how organizational structure and cultural dimensions affect managers' behaviors.

Organization as a context is itself part of the surrounding culture. The present study tapped impact of the surroundings cultures at the levels of states. Gujarat was found to be more developed states than Bihar on the basis of hard evidences. Therefore, the developed state was considered to be in enabling context and the less developed state of Bihar was considered to be disabling context. A better strategy for more comprehensive understanding of contexts on managers' behavior should include both organizational context and its surrounding context in one study.

\section{References}

Census of India. (2011). Govt. of India. Chapter 6 State Literacy, p.14.

Gudykunst, W. B. (1983). Intercultural communication theory. Beverly Hills, CA: Sage.

Gupta, R. K. (2002). 'Prospects of Effective Teamwork in India: Some Cautionary Conjectures from Cross-Cultural Perspectives'. Indian Journal of Social Work, 50(2), 220-236.

Hall, E. T. (1976). Beyond culture: New York: Doubleday.

Hall, E., \& Hall, M. (1990). Understanding culture differences: Germans, French andAmericans. Yarmonth: Intercultural Press.

Hughes, M. L. (2002). A theoretical and empirical analysis of Chinese and Indian negotiating behaviour. Unpublished Master Thesis, Aarhus School of Business. Aarhus, Denmark.

Markus, G., \& Kitayama, S. (1991). Culture and self: Implications for cognition, emotion, and motivation. Psychological Review, 98, 224-253.

Miller, J. G. (1984). Culture and the development of everyday social explanation. Journal of Personality and Social Psychology, 46, 961-978.

Ramanujan, A. K. (1989). Is there an Indian way of thinking? An informal essay. Contributions to Indian Sociology, 25, 41-58.

Roland, A. (1988). In search of self in India and Japan: Towards a cross-cultural psychology. Princeton, NJ: Princeton University Press.

Sinha, J. B. P. (1970). Development through behaviour modification. Bombay: Allied Publisher.

Sinha, J. B. P. (1974). A case of reversal in participative management. Indian Journal of Industrial Relations, 10, 179-187.

Sinha, J. B. P. (2009). The shifting mindset of Indians. In G Misra (Ed.), Discipline of Psychology in the series "History of Indian Science, Philosophy and Culture" (General Editor D P Chattopadhyaya).

Sinha, J. B. P. (2010). Living and Doing Psychology. Psychology \& Developing Societies, 22(1), 95-120.

Sinha, J. B. P., \& Kanungo, R. N. (1997). Context sensitivity and balancing in organizational behaviour. International Journal of Psychology, 32, 93-105.

Sinha, J. B. P., \& Pandey, A. (2007). Indians' mindsets and the conditions that evoke them. Psychological Studies, 52, 1-13.

Sinha, J. B. P., Singh, S., Gupta, P., Srivastava, K. B. L., Sinha, R. B. N., Srivastava, S., et al. (2010). An exploration of the Indian mindset. Psychological Studies, 55, 3-17. 
Sinha, J. B. P., \& Sinha, D. (1990). Role of social values in Indian organizations. International Journal of Psychology, 25, 705-714.

Sinha, J. B. P., \& Sinha, D. (1995). "Role of social values in Indian organizations". In H. S. R. Kao, D. Sinha, and Ng Sek-Hong (Eds.). Effective organizations and social values, New Delhi: Sage pp. 164-173.

Sinha, J. B. P., Sinha, R. B. N., Bhupatkar, A. P., Anand Gupta, P., Gupta, P., Panda, A., Singh, S., SinghSenGupta, S., \& Srinivas, E. S. (2004). Facet of societal and organizational cultures and managers work related thoughts and feelings. Psychology and Developing Societies, 16: 125.

Sinha, J. B. P., Sinha, T. N., Verma, J., \& Sinha, R. B. N. (2001). Collectivism coexisting with individualism: An Indian scenario. Asian Journal of Social Psychology, 4, 133-145.

Sinha, S. R. (2012). Context sensitivity as a factor of organizational behaviour. Social Engineer, 13, 71-79.

Triandis, H. C. (1994). Theoretical and methodological approaches to the study of collectivismindividualism. In U. Kim, H. C. Triandis, C. Kagicibasi, S. C. Chok, \& G. Yoon (Eds.). Individualism and collectivism: Theory, method, and application (pp 44-51). Thousand Oaks: Sage.

Trompenaars, F. (1993). Riding the waves of culture: understanding cultural diversity in. London: The economic Books. 
INTERNATIONAL JOURNAL OF ACADEMIC RESEARCH IN PSYCHOLOGY

Vol. 4, No. 1, 2017, E-ISSN: 2312-1882 @ 2017 KWP

Table 1 Two-Way ANOVA Displaying Effects of Contexts, Persons \& Locations on Managers'

\begin{tabular}{|c|c|c|c|c|c|c|c|}
\hline Statements & $\begin{array}{l}\text { Contex } \\
t \\
(\mathrm{C})^{\mathrm{a}}\end{array}$ & $\begin{array}{l}\text { Perso } \\
\text { n } \\
\text { P) }\end{array}$ & $\begin{array}{l}\text { Locatio } \\
\mathbf{n} \\
\text { b }\end{array}$ & $C \times P^{a}$ & $C \times L^{b}$ & $P \times L^{b}$ & $C \times P \times L^{b}$ \\
\hline $\begin{array}{l}\text { 1. Follow rules and } \\
\text { regulations meticulously }\end{array}$ & $5.47^{*}$ & 2.35 & $4.76 * *$ & .22 & .21 & .22 & 1.50 \\
\hline $\begin{array}{l}\text { 2. Come up with new } \\
\text { ideas that improved } \\
\text { performance }\end{array}$ & .37 & .02 & .09 & .03 & .21 & .21 & .42 \\
\hline $\begin{array}{l}\text { 3. Kept Superiors } \\
\text { pleased telling how } \\
\text { ideal bosses they were. }\end{array}$ & .99 & 1.19 & 1.84 & $4.60 *$ & .02 & .55 & $3.97 *$ \\
\hline $\begin{array}{l}\text { 4. More \& more work } \\
\text { completed on schedule. }\end{array}$ & .87 & .37 & $4.91 * *$ & .02 & 2.70 & .09 & .12 \\
\hline $\begin{array}{l}\text { 5. Inspired subordinates } \\
\text { to get best out of them. }\end{array}$ & $4.63^{*}$ & 3.38 & .79 & $5.63^{* *}$ & $\begin{array}{c}15.95^{*} \\
*\end{array}$ & $\begin{array}{c}13.43^{*} \\
*\end{array}$ & 1.23 \\
\hline $\begin{array}{l}\text { 6. Manipulate records to } \\
\text { show his better } \\
\text { performance. }\end{array}$ & .23 & .61 & .59 & $7.22 * *$ & .68 & .47 & .60 \\
\hline 7. Just lucky. & 2.95 & .21 & 3.26 & $\begin{array}{c}10.09 * \\
*\end{array}$ & .36 & .65 & 1.44 \\
\hline $\begin{array}{l}\text { 8. Visit his superiors at } \\
\text { their residence and offer } \\
\text { services. }\end{array}$ & 1.27 & 3.46 & .65 & $5.28 *$ & .12 & .66 & .48 \\
\hline $\begin{array}{l}\text { 9. High technical } \\
\text { competence and high } \\
\text { motivation. }\end{array}$ & 2.74 & .36 & 1.29 & 1.61 & 2.46 & .21 & .19 \\
\hline $\begin{array}{l}\text { 10. Favored } \\
\text { subordinates who } \\
\text { praised him publicly. }\end{array}$ & .10 & $5.13^{*}$ & .63 & 3.16 & .28 & .14 & 1.53 \\
\hline $\begin{array}{l}\text { 11. Maintained } \\
\text { connections contractors } \\
\text { who lobbied for him to } \\
\text { management. }\end{array}$ & 1.37 & 1.90 & 2.20 & .39 & .67 & .09 & .50 \\
\hline
\end{tabular}

Behavior

$\mathrm{N}=150,{ }^{*} p<.05,{ }^{* *} p<.01,{ }^{\mathrm{a}} \mathrm{df}=1 / 147{ }^{\mathrm{b}} \mathrm{df}=2 / 147$ 
INTERNATIONAL JOURNAL OF ACADEMIC RESEARCH IN PSYCHOLOGY

Vol. 4, No. 1, 2017, E-ISSN: 2312-1882 @ 2017 KWP

Table 2 Mean \& SD (parenthesis) of Managers' Success Behaviors in Disabling and Enabling Contexts.

\begin{tabular}{|l|l|l|l|l|}
\hline \multirow{2}{*}{ Statements } & \multicolumn{2}{|c|}{ Ashok } & \multicolumn{2}{c|}{ Vivek } \\
\cline { 2 - 5 } & Disabling & Enabling & Enabling & Disabling \\
\hline $\begin{array}{l}\text { 1. Follow rules and } \\
\text { regulations meticulously }\end{array}$ & $1.79(.63)$ & $1.68(.70)$ & $1.84(.76)$ & $1.77(.71)$ \\
\hline $\begin{array}{l}\text { 2. Come up with new ideas that } \\
\text { improved performance }\end{array}$ & $1.60(.68)$ & $1.58(.67)$ & $1.61(.61)$ & $1.58(.66)$ \\
\hline $\begin{array}{l}\text { 3. Kept Superiors pleased telling } \\
\text { how ideal bosses they were. }\end{array}$ & $2.27(.87)$ & $\mathbf{2 . 4 1 ( . 8 8 )}$ & $2.42(.88)$ & $2.36(.89)$ \\
\hline $\begin{array}{l}\text { 4. More \& more work completed } \\
\text { on schedule. }\end{array}$ & $1.97(.71)$ & $2.02(.79)$ & $2.01(.73)$ & $\mathbf{2 . 0 4 ( . 8 3 )}$ \\
\hline $\begin{array}{l}\text { 5. Inspired subordinates to get } \\
\text { best out of them. }\end{array}$ & $1.59(.65)$ & $\mathbf{1 . 6 2 ( . 6 0 )}$ & $1.63(.65)$ & $\mathbf{1 . 4 5}(.68)$ \\
\hline $\begin{array}{l}\text { 6. Manipulate records to show } \\
\text { his better performance. }\end{array}$ & $2.78(.97)$ & $2.60(.94)$ & $2.63(.95)$ & $\mathbf{2 . 7 7 ( . 9 4 )}$ \\
\hline \begin{tabular}{l} 
7. Just lucky. \\
\hline
\end{tabular} & $2.61(.88)$ & $2.50(.83)$ & $2.41(.86)$ & $\mathbf{2 . 6 6 ( . 8 4 )}$ \\
\hline $\begin{array}{l}\text { 8. Visit his superiors at their } \\
\text { residence and offer services. }\end{array}$ & $2.83(.89)$ & $2.66(.89)$ & $2.65(.91)$ & $\mathbf{2 . 7 1 ( . 9 5 )}$ \\
\hline $\begin{array}{l}\text { 9. High technical competence } \\
\text { and high motivation. }\end{array}$ & $1.67(.64)$ & $1.55(.61)$ & $\mathbf{1 . 6 3 ( . 6 3 )}$ & $\mathbf{1 . 6 3 ( . 6 3 )}$ \\
\hline $\begin{array}{l}\text { 10. Favored subordinates who } \\
\text { praised him publicly. }\end{array}$ & $2.47(.84)$ & $2.37(.83)$ & $2.30(.85)$ & $\mathbf{2 . 3 7 ( . 8 6 )}$ \\
\hline $\begin{array}{l}\text { 11. Maintained connections } \\
\text { contractors who lobbied for him } \\
\text { to management. }\end{array}$ & $2.19(.87)$ & $2.12(.87)$ & $\mathbf{2 . 2 2 ( . 9 0 )}$ & $\mathbf{2 . 2 1 ( . 9 4 )}$ \\
\hline
\end{tabular}

